\title{
Design enquanto mediador colaborativo: a construção da Revista Folhear
}

\section{Design as collaborative mediator: the Folhear magazine's construction}

\author{
Maressa Stephany Carvalho Santos ${ }^{[1]}$, \\ Andreia Bordini de Brito ${ }^{[2]}$, \\ Paula Garcia Lima ${ }^{[3]}$
}

\begin{abstract}
Resumo: Com base nos princípios de design colaborativo, este trabalho apresenta as práticas projetuais da criação da terceira edição da revista Folhear, uma publicação anual com a intenção de evidenciar o lado mediador e colaborativo do design, a partir da sua junção com a botânica. Na edição aborda-se como tema a afetividade no cultivo de plantas, tendo como alvo um público popular interessado pela temática, porém sem conhecimentos específicos sobre o assunto. Nesse sentido, o objetivo principal deste trabalho é abordar as metodologias utilizadas na criação da publicação, trazendo reflexões e resultados sobre o processo, bem como a sua finalização. A partir desse objetivo maior, outros são traçados, tais como: compreender a teoria por trás da revista, identificar a metodologia projetual utilizada e apresentar a relevância do projeto gráfico/editorial realizado. 0 trabalho apoia-se na metodologia proposta por Shea (2012), a qual propõe diversos passos para criar projetos de design colaborativos. Por fim, retrata-se o feedback recebido ao retornar o projeto à comunidade participante, principalmente ao grupo "Tudo Sobre Plantas", uma comunidade digital da rede social Facebook, onde o conteúdo da revista foi coletado de modo colaborativo.
\end{abstract}

Palavras-chave: Colaboração. Botânica. Design editorial.

[1] Graduada de Design Gráfico, UFPEL. maressastcarvalho@gmail.com

[2] Doutora em Engenharia Agrícola e Ambiental.bordinibrito@gmail.com

[3] Doutora em Memória Social e Patrimônio

Cultural, UFPEL.paulaglima@gmail.com 
Abstract: Based on the principles of collaborative design, this work presents the design pratices of the third edition of Folhear magazine, an annual publication with the intention of highlighting the mediating and collaborative side of design, from its junction with botany. In the edition, affectivity in cultivations is the chosen theme, targeting a public interested in the subject, but without specific knowledge about it. In this sense, the main objective of this work is to approach the methodologies used in the creation of the magazine, bringing reflections and feedback about the process, as well as its completion. From this larger objective, others are outlined, such as: understanding the theory behind the publication, identifying the design methodology used and presenting the relevance of the graphic/editorial project created. The work is based on the methodology proposed by Shea (2012), which uses several steps to create collaborative design projects. Finally, the work is found in the group "All About Plants", a digital community of the social network Facebook, where the content of the magazine was collaboratively collected.

Keywords: Collaboration. Botany. Editorial design.

\section{INTRODUÇÃO}

O Design é interdisciplinar e colaborativo em sua origem. Uma das principais características de um projeto de design é, como diz Fontoura (2011), "o envolvimento de inúmeros conhecimentos de domínios distintos", o que situa o design numa posição de constante conjunção com outras áreas do conhecimento para a criação de projetos.

Ao projetar, além de levar em consideração as inúmeras condicionantes técnicas, o designer considera também o universo de necessidades dos usuários. Isso implica um acervo de conhecimentos oriundos de diversas áreas (FONTOURA, 2011, p. 92).

Fontana; Heemann; Gomes Ferreira (2012), complementam ao apontar que o movimento de interseção de áreas não é exclusivo do design, mas sim fruto da globalização humana.

O termo, não sendo exclusividade da área do Design, aparece em pesquisas de várias áreas. Esta presença em diferentes áreas de estudo e em diferentes contextos, mostra que a colaboração é um fenômeno inerente aos processos humanos, porém tornando-se algo tratado difusamente ou despercebida em decorrência do senso comum.

(FONTANA; HEEMANN; GOMES FERREIRA, 2012, p. 1). 
A partir disso, este artigo tem como foco as práticas projetuais da criação da terceira edição da revista Folhear, que apresenta o design como colaborativo e mediador, trazendo como tema a botânica, a partir da compilação de dados advindos de uma comunidade colaborativa. A Folhear é uma revista criada pela autora durante o período de formação no curso de design gráfico da Universidade Federal de Pelotas, como um meio de unir suas paixões, após perceber na botânica um modo de personalizar sua casa, transformando-a em refúgio após se mudar para uma cidade que não conhecia.

Em suas primeiras duas edições, a Folhear tinha a intenção de ser uma revista de arte sobre uma espécie de planta, apresentando-a, a partir do olhar refinado de uma designer, ao público geral. Ambas edições tiveram cerca de duas cópias impressas, porém não ultrapassaram o ambiente acadêmico das salas de aula.
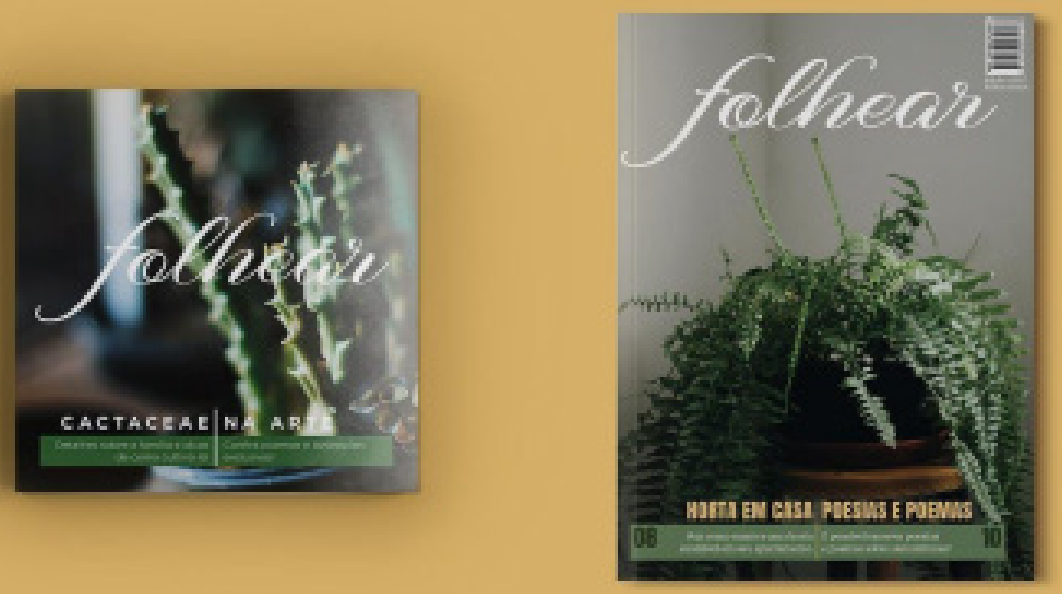

Figura 1: Capas das demais edições da Folhear. Fonte: Acervo da autora, 2017. 
Em sua última edição, e tema deste artigo, a Folhear traz como tema o cultivo de plantas, e assume um caráter ainda mais colaborativo ao coletar experiências afetivas acerca do cultivo, de uma forma democrática e coletiva, tendo como alvo um público que não tem conhecimentos específicos de botânica. Ou seja, busca-se introduzir o tema ao cotidiano da população interessada pelo mesmo, facilitando assim o acesso a esse conteúdo.

Tendo isto em vista, para construção da publicação, questionou-se o seguinte: seria possível organizar um material coletivo para uma revista, onde os dados coletados viriam da própria comunidade, através de um processo colaborativo? Com base nessa questão e no propósito deste artigo, o principal objetivo é abordar as metodologias utilizadas na criação da publicação, trazendo reflexões e resultados sobre o processo e a finalização do projeto. A partir desse objetivo, surgem outros objetivos, como compreender a teoria por trás da revista, identificar a metodologia projetual utilizada e apresentar a relevância do projeto gráfico/editorial realizado.

A importância deste artigo se dá pelo estudo das diversas formas de colaboratividade dentro da área do design, assim como a estimulação da produção de conteúdo na junção da mesma com a botânica. Além disso, ao retratar a experiência da autora durante o processo de criação da revista, é possível perceber a importância da visão do design enquanto mediador não só entre áreas, mas também pessoas e relações.

Tendo em vista a estruturação deste artigo, inicialmente contextualiza-se as áreas abordadas na terceira edição da FoIhear, para que se entenda da teoria que fundamenta o projeto. Após isso, aborda-se a metodologia projetual utilizada, a partir dos estudos de Shea (2012) e das parcerias colaborativas. Finaliza-se então, com a apresentação do projeto gráfico/editorial da publicação, bem como a recepção do material pelo público a que foi exposto. 


\section{CONTEXTUALIZAÇÃo}

Primeiramente, antes de adentrarmos o projeto gráfico da Folhear e as experiências da autora, percebe-se a necessidade de contextualizar as áreas que o estruturaram: botânica, design editorial e design colaborativo. Assim sendo, a botânica pode exercer um papel afetivo na vida das pessoas. É comum materializar no cultivo de plantas os momentos ou experiências vividos, além de expressões culturais e saberes populares. A etnobotânica é a ciência que abrange estudos sobre as relações estabelecidas entre comunidades humanas e o componente vegetal. Segundo Carniello (2010), essas relações normalmente são modeladas pela história da comunidade, pelo ambiente físico, social e ainda pelas qualidades inerentes às próprias plantas.

[...] É no território que o homem constrói a sua identidade e onde desenvolve sua cultura apropriando-se do entorno. É na dimensão do espaço que interage, cria seu patrimônio, cultiva sua cultura e herda os seus costumes, atravessando a dimensão temporal. Entendemos que o patrimônio está intimamente ligado à relação humana com a natureza. Além da dimensão científica, o meio ambiente também possui uma dimensão social e humana, que permite entender as relações das sociedades com a natureza que as rodeia (FLÓREZ, 2011, p. 33).

A partir do estudo etnobotânico de Lobato (2017), onde analisa as representatividades das plantas ornamentais em 189 quintais urbanos do bairro Mutirão, em Abaetetuba - Pará, percebe-se que, segundo os interlocutores, as espécies cultivadas pertencem às categorias estética (58\%), mística (22\%), afetiva (8\%), comercialização (6\%) e sombreamento (6\%). Os quintais do Mutirão ressignificam seus espaços, nutrindo o imaginário urbano cada vez mais escasso de tradições, com suas informações ornamentais de crenças e histórico-culturais que vêm das comunidades periféricas, preenchendo a expectativa de uma experiência entre o humano e o natural.

Tendo em vista o foco da revista Folhear, a área de especialização do design que a mesma abrange é a editorial, que, 
de acordo com Damasceno (2013), se dedica à elaboração de projetos para publicações - edições como livros, jornais e revistas -, destacando a qualidade de conferir expressão e personalidade ao conteúdo, envolvendo os leitores por meio da apresentação visual, a fim de promover o interesse pela leitura.

Entrando em circulação depois do jornal, as revistas estão, desde seu início, diretamente ligadas a alta sociedade. Surgiram como um meio de intelectuais e cientistas discutirem suas ideias, e após a Revolução Industrial, como modo de entretenimento da elite (FETTER, 2011). Foi apenas no século XIX, com o desenvolvimento dos centros urbanos e a migração da massa trabalhadora para as cidades, que possibilitou na alfabetização da população e um consequente aumento potencial de leitores da classe média.

No ano de 1893, três editores americanos passaram a vender suas revistas por 10 e 15 centavos, em vez dos 25 cobrados na época. Assim, nasceu a revista moderna, de preço baixo, apelo popular e grande circulação. Criou-se, então, o conceito de circulação de massa, o que fez surgir o maior mercado de revistas do mundo, que estabeleceu modelos imitados em todo o mundo (FETTER apud ALI, 2011, p. 26).

De acordo com Fetter (2011), na história da imprensa, aos os jornais coube o importante papel de democratizar a informação, enquanto as revistas desempenharam o papel de informar e entreter, mostrando culturas e influenciando comportamentos no mundo todo. Rapidamente, as revistas se difundiram, tornando-se uma vanguarda do design gráfico, visto que fomentavam outras modalidades de envolvimento corporal, de relações com o espaço físico e de sociabilidade em torno da leitura, proporcionando discussões acerca das relações entre produção editorial e cultura (GRUSZYNSKI, 2015).

Conforme citado anteriormente, no âmbito de design editorial, a principal intenção é comunicar uma ideia ou narrar histórias por meio de uma sequência de páginas com textos e imagens ordenadas. Para Fetter (2011), mais do que apresentar conteúdos, tornou-se necessário desenvolver estratégias 
de desenvolvimento de conteúdo e produção e, nesse sentido, compreende-se que o que esta edição propõe - acerca da compilação de conteúdos de forma a exaltar a participação dos colaboradores, tornando-os partícipes ativos no processo-, cumpre taticamente este papel indicado pelo autor. Assim, surge a ideia de projeto gráfico, pois o desenvolvimento de publicações passa a exigir planejamento e articulação de diferentes elementos, vendo as páginas impressas como um espaço a ser arquitetonicamente modulado.

Ao tratar-se de design colaborativo, é necessário ter em mente o cenário no qual surgiu. Para Coutinho (2010), foi a partir de uma nova realidade de consumo, onde a criatividade e a inovação são os principais pilares de um projeto, que o design colaborativo aparece como uma abordagem alternativa para tornar o método de projetação mais humanizado, assim como valorizar ainda mais as interações durante o processo. Fontana (2012) complementa, afirmando que o termo se tornou mais frequente no design ao se tornar inviável e indesejável um profissional dominar todo o conhecimento necessário para o desenvolvimento de um sistema complexo.

Deste modo, ao definir design colaborativo, refere-se ao processo de envolver pessoas com perfis distintos no processo de design, com o objetivo de alcançar soluções não lineares para os mais variados tipos de problemas. É importante ressaltar que a colaboração não necessariamente é exclusiva a designers, pelo contrário; Pimenta (2017) defende que o potencial para chegar a soluções inovadoras será tanto maior quanto a diversidade do grupo de pessoas envolvidas no projeto.

É um esforço recíproco entre pessoas de iguais ou diferentes áreas de conhecimento, separadas fisicamente ou não, com um objetivo comum de encontrar soluções que satisfaçam a todos os interessados. [...] A colaboração visa produzir um produto e/ou serviço consistente e completo através de uma grande variedade de fontes de informações com certo grau de coordenação das várias atividades implementadas. Esse processo depende da relação entre os atores envolvidos, 
da confiança entre eles e da dedicação de cada parte

(FONTANA; HEEMANN; GOMES FERREIRA, 2012, p. 5).

As discussões acerca da colaboratividade possível em um projeto vão além com as ideias propostas por Freire (apud BRANDÃO, 1990), de que uma pesquisa colaborativa só teria sentido na relação dinâmica entre a objetividade e subjetividade de sua realidade, colocando o público como sujeito participante do seu próprio desenvolvimento, e não como mero objeto de pesquisa.

No design, isso seria aplicado quando Lupton (2013) diz sobre a necessidade dos profissionais se verem não como controladores do resultado final, mas sim como desencadeadores de um processo que envolve ativamente o público, com um caráter de mediador, conceito sustentado por Gruszynski:

Destacamos o caráter mediador da atividade ao atuar como articuladora formal/visual de conteúdos que são concebidos preliminarmente por escritores/autores, jornalistas etc. e dirigidas a leitores. Inúmeras camadas de significados vão sendo adicionadas aos "conteúdos originais" que dão início aos processos de produção, na medida que definições vão sendo realizadas, tendo em vista um leitor/público imaginado desde o início dos procedimentos (GRUSZYNSKI, 2015, p. 576).

Tendo em vista os dados apresentados, a terceira edição da Folhear tem o intuito de abranger o cultivo de plantas através de um modo colaborativo não apenas em sua metodologia de coleta de conteúdo, como também através da valorização de todas as etapas envolvidas no processo de produção da revista. Além disso, se utilizando da democratização da informação difundida pelos produtos impressos e das socializações possibilitadas pelo uso da tecnologia digital.

\section{DESENVOLVIMENTO}

Abordando a metodologia projetual que fundamentou a terceira edição da Folhear, tem-se os estudos de Shea (2012) 
em Design for social change ${ }^{[3]}$, onde propõe 10 estratégias: Imersão, Construção de confiança, Sinceridade, Priorização do processo, Confronto a controvérsia, Identificação das forças da comunidade, Projeção da voz da comunidade, e por fim, Perpetuação do engajamento. Para a revista, utilizou-se as etapas de imersão, construção de confiança, identificação das forças e projeção da voz da comunidade e perpetuação do engajamento.

$\mathrm{Na}$ etapa inicial da metodologia, imersão, é sugerido que o designer se insira no grupo para o qual o projeto é intencionado. Ao se aproximar dos mesmos, é importante se manter atento tanto a ações quanto observações, abrindo seus horizontes para novas perspectivas e descobertas, deixando-se acessível para um diálogo. No presente projeto, a etapa de imersão se deu com a entrada da autora no grupo online da plataforma Facebook, escolhido para implementar a metodologia. O grupo Tudo Sobre Plantas foi escoIhido graças à interação de seus 7,7mil membros, com cerca de 10 postagens ao dia.

Ao realizar o pedido para fazer parte da comunidade, foi necessário responder uma pergunta sobre o motivo do interesse no mesmo, como uma forma de triagem ou de seleção dos membros. A resposta da autora foi sincera conforme os preceitos de Freire (apud BRANDÃO, 1990); disse que pretendia colher informações para o presente trabalho de graduação. Ao ser aceita, a autora foi rapidamente felicitada pelo principal moderador com uma postagem aos novos membros. O sentimento acolhedor foi instantâneo para as 25 pessoas que foram bem recebidos pelos comentários da postagem, mantendo a ideia de que o grupo é uma comunidade amigável e familiar.

Seguindo a metodologia, é recomendado que se aproveite essa abertura para ganhar a confiança do grupo escolhido. Para isso, é necessário mostrar que se está compromissado com o projeto e seu objetivo principal. Segundo Shea (apud TAVARES, 2018), ganhar a confiança da comunidade o ajuda-
[4] Traduzido pela autora: "Design para mudanças sociais". 


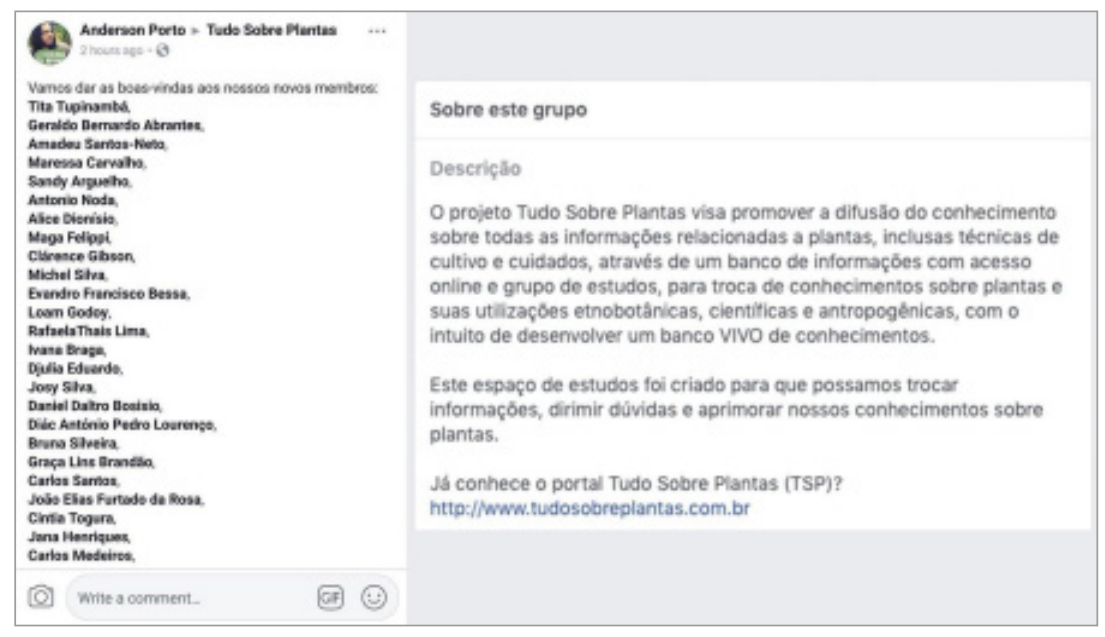

rá a conectar-se emocionalmente com os membros, evitando ser tratado como um membro externo ao grupo. Esta etapa se deu com duas outras postagens da autora antecedentes à publicação do formulário digital, mostrando o engajamento da mesma com o grupo, e não somente com a presente pesquisa.

Como terceira estratégia, utiliza-se a identificação de forças e projeção da voz da comunidade, conjuntamente. Ao identificar as forças da comunidade, é indicado fazer uma análise sobre o grupo, percebendo seus problemas e buscando soluções com a ajuda deles mesmos, enaltecendo seus pontos fortes, ou seja, utilizar seus talentos e potenciais em prol de um projeto integrado.

Ao projetar a voz da comunidade, indica-se mesclar as percepções do grupo com as do designer, resultando em soluções oriundas do coletivo e da co-criação, possibilitando inclusive uma participação do grupo na execução do projeto, pois segundo Tavares (2018), na maioria dos casos, o mais significativo será o potencial modificador do projeto, e não o resultado visual alcançado.

Tendo isto em vista, adaptando esses ideais para o projeto, fez-se uma triagem do conteúdo do grupo, desenvolvendo-se um método de busca entre as datas de outubro de 2016 a outubro de 2018 (mês em que o projeto foi criado). Essa triagem
Figura 2: Fotos de tela do grupo "Tudo Sobre Plantas". Fonte: Acervo da autora, 2018. 
é justificada pelo maior interesse demonstrado por parte dos membros da comunidade, provando-a de extrema importância e relevância para estar entre o conteúdo da revista.

De acordo com a autora, a melhor forma de verificar o engajamento dos posts a serem selecionados como conteúdo da revista seria a quantidade de comentários recebidos, tendo em vista que os membros do grupo estariam contribuindo e compartilhando com o assunto ali expressado, enquanto curtidas representam um interesse demasiado automático ou mecanizado.

Na última etapa da metodologia, perpetuação do engajamento, Shea (2012) enfatiza a importância de construir uma relação de amizade com o grupo estudado, mantendo contato após a realização do projeto, além de acompanhar e avaliar os reflexos produzidos pelo mesmo, sejam eles positivos ou negativos. Sendo assim, a autora permanece ativa no grupo mesmo após a coleta de dados e os resultados da presente pesquisa, compartilhando saberes de sua vivência e relação pessoal com botânica e cultivo.

Incorporando os preceitos de design colaborativo, acrescenta-se à metodologia a colaboração também no projeto gráfico da revista, convidando outros profissionais para fazer parte da construção da mesma, contribuindo com seu olhar acerca dos conteúdos gerados, produzindo fotografias, ilustrações, poemas ou diversos outros modos de colaboração como por exemplo editoração e redação das manchetes a serem utilizadas.

Não se pode esquecer, porém, da necessidade deste projeto retornar para a comunidade de onde surgiu, de modo que foi criado uma solução para que o compartilhamento digital se faça possível, a partir dos preceitos já vistos acerca da fusão digital com os meios editoriais. Projetou-se então, cartas que sintetizam o conteúdo informativo da revista e são de fácil compartilhamento, sendo essas acessadas a partir de hiperlinks no sumário, no caso do arquivo pdf, ou do código presente nas versões digitais e impressas. 
Tratando da metodologia prática, todo o processo de construção da edição se fez de modo colaborativo. Desde o primórdio, a autora contou com contribuições não somente da banca orientadora, mas também de amigos e conhecidos que foram se agregando ao projeto. Surgiram referências em conversas de bar, em citações de professores durante aulas, ou em links compartilhados por redes sociais.

Apesar de todas as contribuições durante o processo de pesquisa e fundamentação teórica, a colaboratividade se tornou clara para a autora na parte prática do projeto gráfico/ editorial, pois o processo estava cada vez mais conectado a todos ao seu redor. Através dos stories ${ }^{[4]}$, decisões foram tomadas em conjunto, a partir de enquetes onde foi possível escolher aspectos como as harmonias tipográficas, os grids e modos de hierarquia de informação do projeto.

Além disso, fotos da encadernação da edição física foram compartilhadas e divididas com a rede virtual da autora, de modo que a relação dos participantes com os resultados alcançados fosse maximizada.

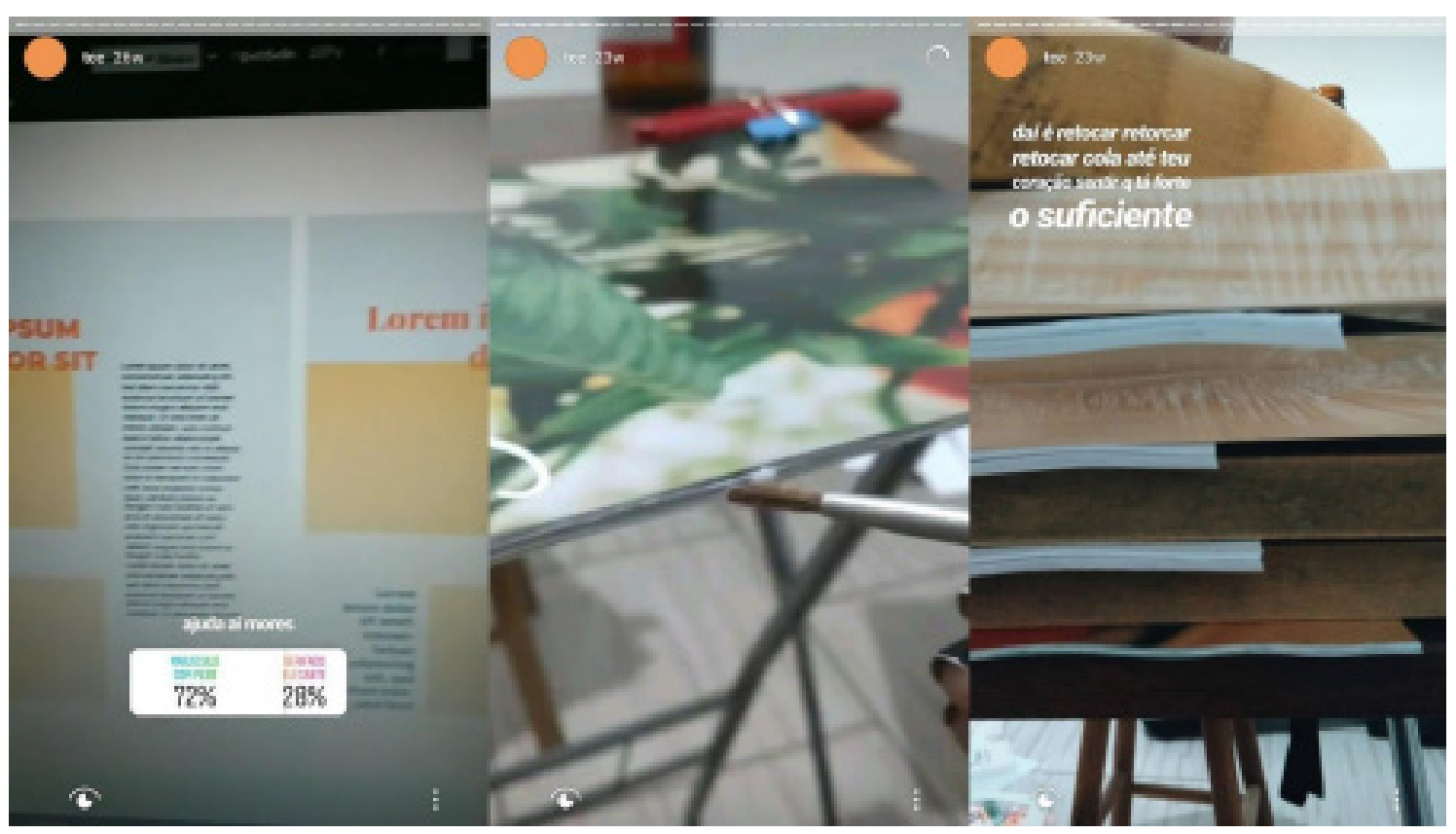

[5] Também chamado de "instastories", é uma função da rede social Instagram lançada em agosto de 2016, em que envia-se um vídeo ou foto, que fica disponível por 24 horas ou, caso deseje, numa posição de destaque no perfil do usuário. Acesse em: https://www. instagram.com/maressices nos destaques "TCC".

Figura 3: Fotos de tela de alguns stories. Fonte: Acervo da autora, 2018. 
Tendo em vista esta participação coletiva nas diversas etapas do projeto, não foi surpresa o feedback gerado com o resultado final, que será abordado posteriormente neste artigo.

\section{RESULTADOS}

A partir de todas as etapas percorridas, apresenta-se o projeto gráfico/editorial da terceira edição da Folhear, bem como seu recebimento pela banca e pela comunidade participante. A linguagem empregada é informal, pois advém principalmente dos conteúdos coletados a partir das publicações mais comentadas e engajadas do grupo Tudo Sobre Plantas. Os conteúdos que não surgem do grupo, são coletados a partir das parcerias mencionadas anteriormente, e mantém esse caráter despretensioso e mais próximo com o público, de modo a criar uma identidade linguística no projeto. A importância da participação de uma redatora no projeto se revela neste momento, pois a partir de sua experiência e olhar profissional, os textos recebem o mesmo tratamento, tornando a leitura mais harmônica e mais fluída.

\section{CULTIVAÇÃo DE ORQUÍDEAS}

Aprenda particularidades e clicas sobre as duas especies mais ilustres Phalaencpsis e Arundina.

¿y Por Anderson Porto Phalaenopsis

phaloenopeds è ums crouices de fisel cultiva Normaimente ela adaptam em estufas quente: com uma luminaclo indreta, e muta

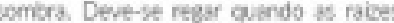
estheram tcaxdio com uma cor prateaca comalmente a cada 7 ou 15 clas 4 adiba cuando estiver sem fores.

A fohagem nào deve ser borrifada, pois e procenca ao acámulo de igua na bace

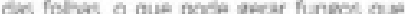
causam doencas e podem abe mesmo
Figura 4: Linguagem utilizada na terceira edição da Folhear. Fonte: Acervo da autora, 2018.

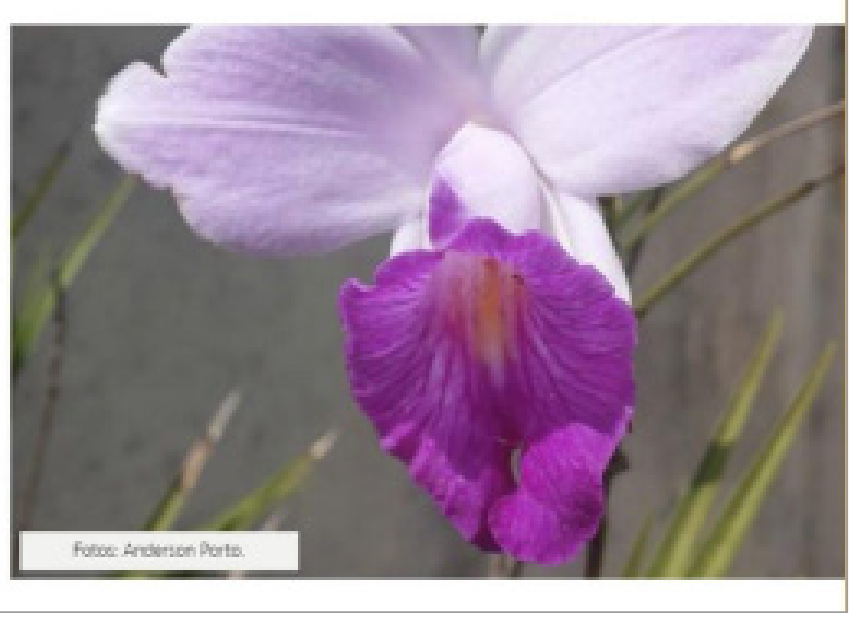


Como estética, mantém-se as identidades já estabelecidas nas demais edições da Folhear, para que não haja um rompimento projetual brusco. Desse modo, a tipografia da capa é conservada, como um logotipo, assim como as características de apresentação das manchetes principais e estilo fotográfico. A parceria com a fotógrafa Corina Minsky permanece, garantindo a identidade fotográfica das outras edições, porém reúne-se fotografias do grupo Tudo Sobre Plantas, expandindo o projeto gráfico-editorial e agregando características novas a ele.

Na capa, é utilizado um elemento criativo: uma sobrecapa de plástico transparente, que complementa as informações, trazendo impresso as manchetes mais interessantes da revista e uma ilustração que, ao se sobrepor à foto utilizada na capa debaixo e ao nome da revista, cria um efeito de sobreposição.

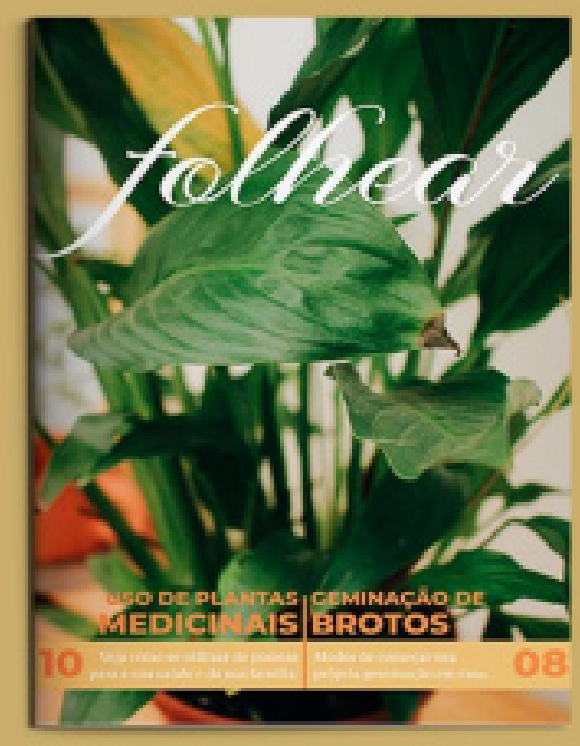

Figura 5: Capa da terceira edição da Folhear. Fonte: Acervo da autora, 2018.

Com base nos estudos dos elementos gráfico/editoriais, o formato é alterado, optando-se por um formato de $210 \mathrm{~mm}$ $x$ 260mm, que é mantido proporcionalmente nas cartas apli- 
cadas digitalmente. A escolha é feita a partir da consideração dos modos de leitura de uma revista, onde é preferível maior espaço gráfico, além do gosto pessoal e estético da autora.

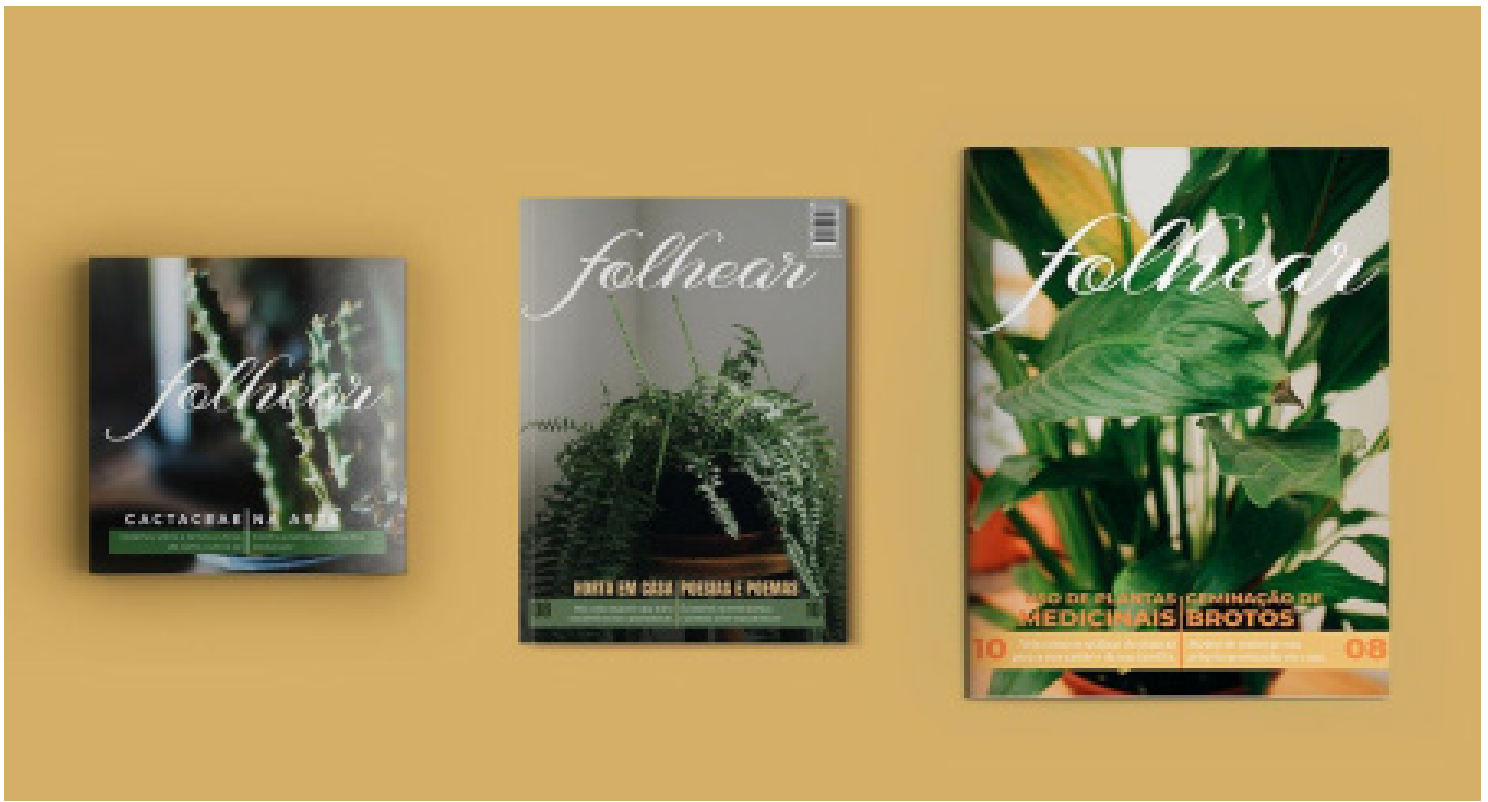

Figura 6: Comparação de formatos das três edições. Fonte: Acervo da autora, 2018.

Aplica-se um grid de quatro colunas, que pode ser considerado mutante, pois permite diversas combinações e é bastante utilizado em revistas populares. Além disso, a escolha por um grid com mais possibilidades se dá para que haja uma harmonia entre o projeto gráfico da revista e do projeto teórico (impresso para a banca avaliadora e disponível também para o público geral). Um grid de quatro colunas permite tanto projetos mais visuais (como as matérias de uma revista), quanto teóricos (como um trabalho de conclusão de curso).

As tipografias utilizadas seguem o padrão proposto pelas demais edições da Folhear, sendo os títulos compostos por uma família com peso negrito, em caixa alta e moderna, enquanto nos textos se utiliza uma família sem serifa, também moderna, porém pensada para ser "transparente" quando usada em textos corridos (como observa-se nas figuras 4 e 

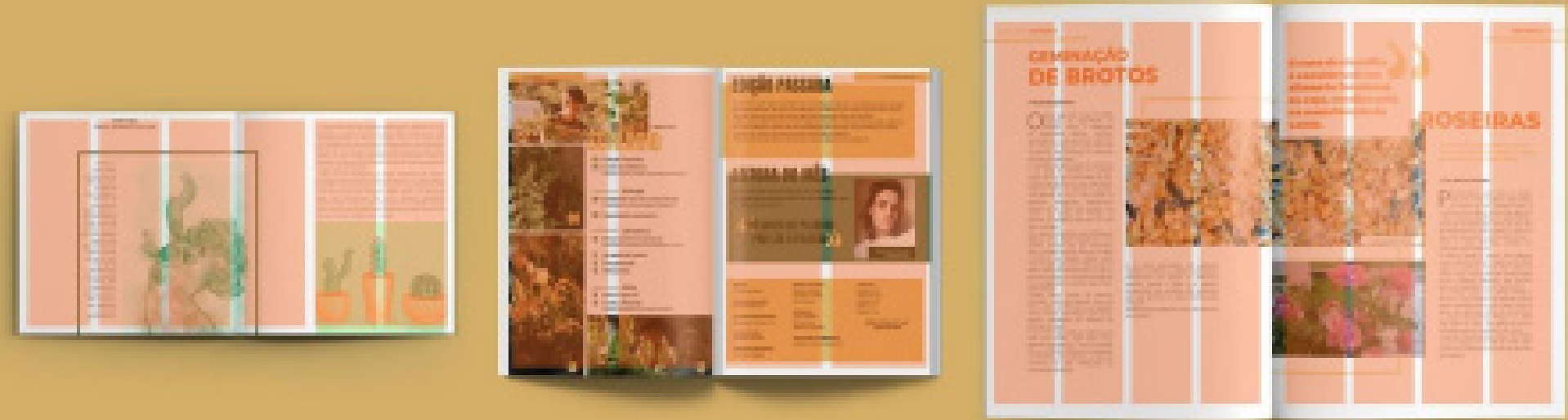

8, respectivamente). Ambas as tipografias são Open Source ${ }^{[5]}$, disponibilizadas pelo Google Fonts ${ }^{[6]}$, e possuem famílias extensas, com variações de peso, largura e espessura.

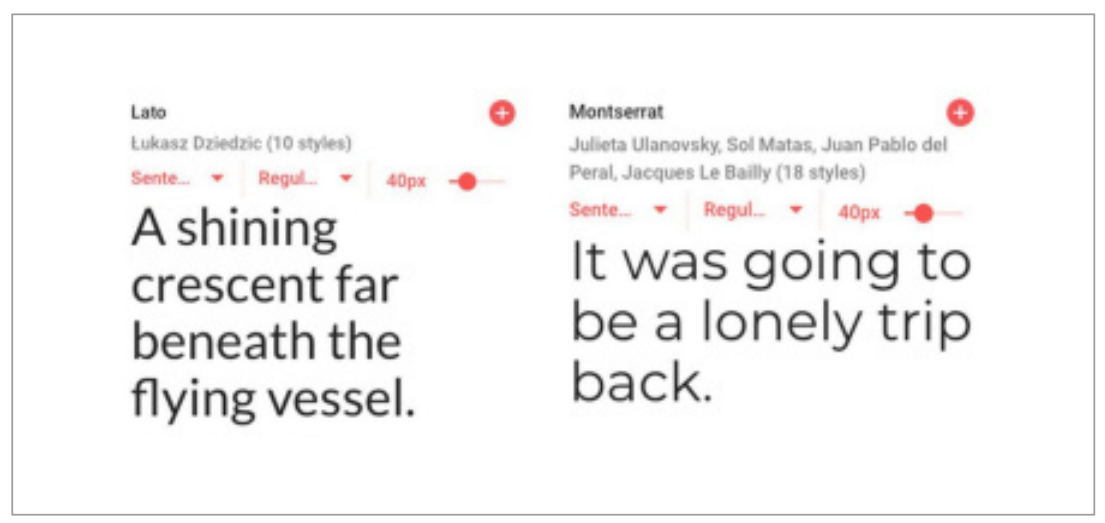

Figura 7: Comparação de grids das três edições. Fonte: Acervo da Autora, 2018.

[6] Um arquivo Open Source é um código fonte disponibilizado e licenciado com uma licença de código aberto no qual o direito autoral fornece o direito de estudar, modificar e distribuir o software de graça para qualquer um e para qualquer finalidade.

[7] É uma biblioteca com mais de 800 fontes livres licenciadas, parte da rede Google.

Figura 8: Tipografias da terceira edição da Folhear. Fonte: Acervo da autora, 2018

As cores da terceira edição da Folhear, não se distanciam das empregadas na segunda edição, mantendo inclusive o tom de amarelo. Opta-se por harmonizar o verde sempre presente nas imagens, o laranja, o amarelo e o preto, criando um esquema análogo, onde todas as cores se encontram próximas no círculo cromático (com exceção do preto, que não é considerado uma cor luz), compartilhando a mesma temperatura, porém garantindo um contraste ao sobrepor as cores extremas (verde e laranja). 


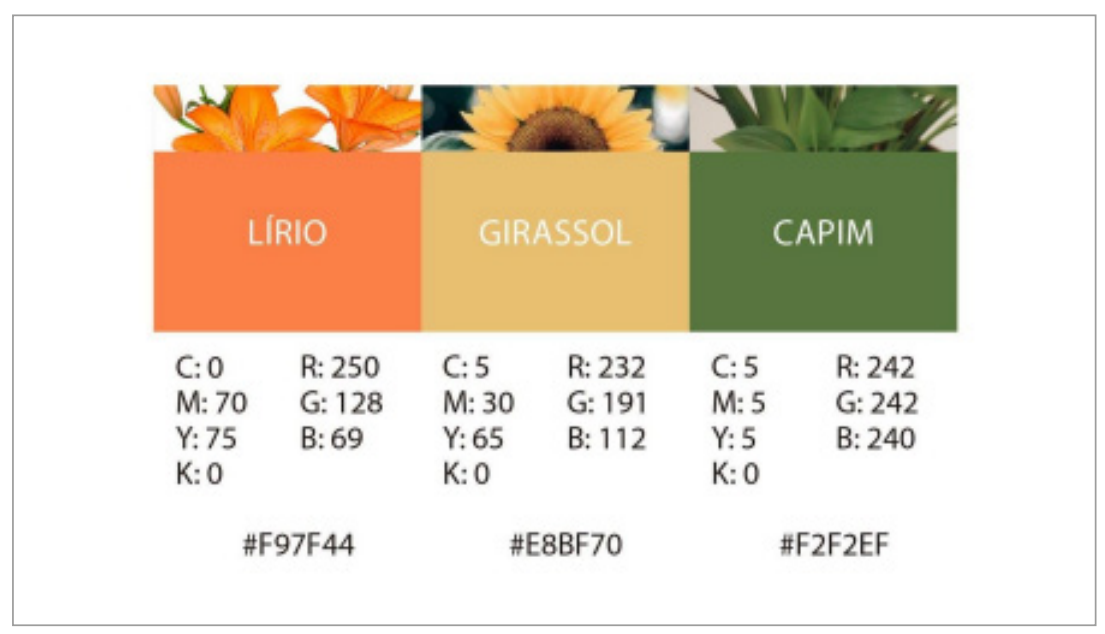

Para concluir, o fator inovação é atribuído à versão digital da revista. Após estudos e pesquisas, chega-se a um modo satisfatório de mesclar a democratização da publicação física à interação digital, a partir da criação de cartas (fotos com o formato digital JPEG, aceito em redes sociais e de tamanho leve e alta compressão) que sintetizam as matérias da revista. Estas cartas podem ser compartilhadas separadamente, e servir o papel de compartilhar a informação de modo mais prático, ou também ser acessadas pela própria revista, a partir de hiperlinks contidos no sumário.

Seguindo o grid e a diagramação propostos no projeto gráfico/editorial da revista, as cartas tem um formato proporcional de $160 \mathrm{~mm} \times 110 \mathrm{~mm}$, e cada matéria recebe uma carta, com exceção da matéria principal, que é separada em três cartas distintas. Desse modo, a revista mantém seu projeto gráfico sem maiores alterações, e agrega outras formas de captar e cativar um público interessado no tema abordado.

Após a finalização do projeto, foi realizada a banca qualificatória, onde as professoras Ana Bandeira e Andreia Bordini, do curso de Design Gráfico da UFPel avaliaram o projeto teórico e o resultado prático da terceira edição da Folhear. Para tal, a autora apresentou o projeto a partir do que considerou os seus pontos principais durante 15 minutos, seguida pe-
Figura 9: Cores da terceira edição da Folhear, 2018. 
las falas das professoras presentes, começando pela orientadora, Paula Garcia Lima.

A banca foi aberta ao público, de modo que os participantes foram convidados a assistir a apresentação do projeto e ver, em primeira mão, o objeto físico. Alguns de fato foram, como por exemplo Corina Minsky e Taís Percone, que colaboraram enquanto fotógrafa e ilustradora, respectivamente. Isso indica que os passos da metodologia proposta foram corretamente seguidos, pois os participantes se envolveram positivamente com o mesmo, obtendo assim, um resultado assertivo.

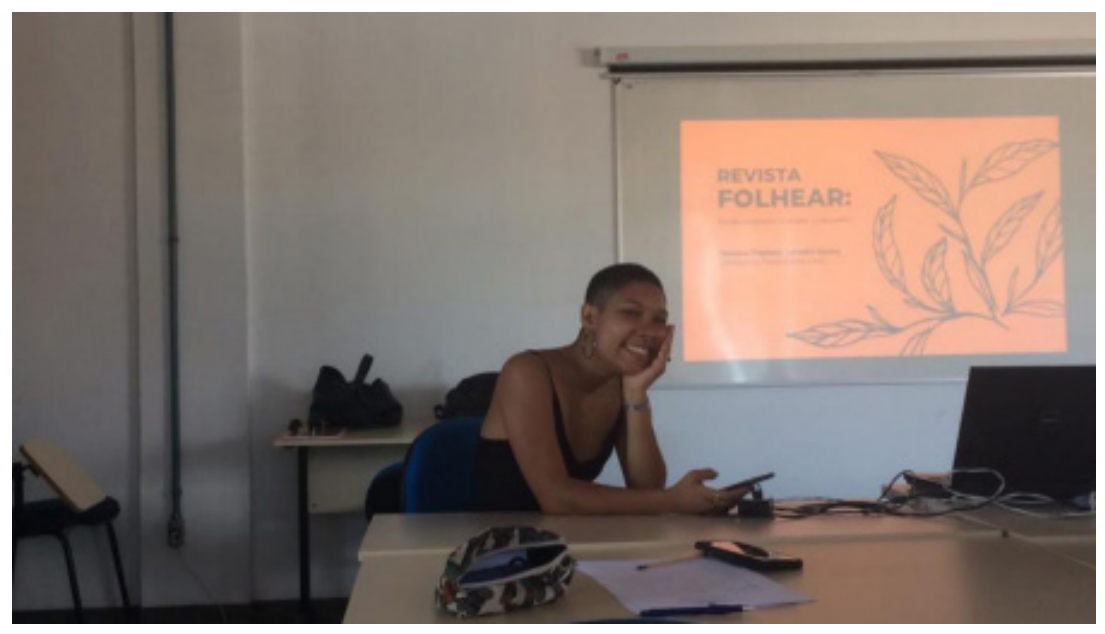

Tendo em vista o curto período em que o projeto foi desenvolvido (de agosto a novembro de 2018), o feedback foi extremamente positivo, tanto por parte da banca avaliadora quanto da plateia presente na apresentação. Alterações foram requeridas, tratando-se em sua maioria de aspectos da estrutura do texto teórico, como foi o caso de acrescentar parágrafos acerca da colaboratividade digital e de uma melhor explicação de como funcionam as cartas digitais.

Não obstante, ao final, o projeto foi avaliado com a nota 10 , e segundo as professoras o mesmo tem forte impacto no
Figura 10: Autora apresentando a banca qualificatória. Fonte: Taís Percone, 2018. 
"modo de enxergar design" e na interdisciplinaridade construída, além de ter constituído uma comunidade própria e engajada durante o desenvolvimento. Com a aprovação da banca e as felicitações dos demais participantes, chegou a hora de devolver o projeto para a comunidade que o compôs, onde coletou-se o conteúdo da revista, completando-se assim a metodologia proposta por Shea (2012) e finalizando oficialmente a revista.

Após um breve distanciamento necessário do projeto, no dia 27 de abril de 2019, a autora realizou duas postagem com todo o material desenvolvido, depois de olhar mais atentamente os detalhes da revista e considerar as sugestões da banca. As postagens foram feitas no grupo Tudo Sobre Plantas e no perfil pessoal da autora, para que alcançasse todos os participantes igualmente.

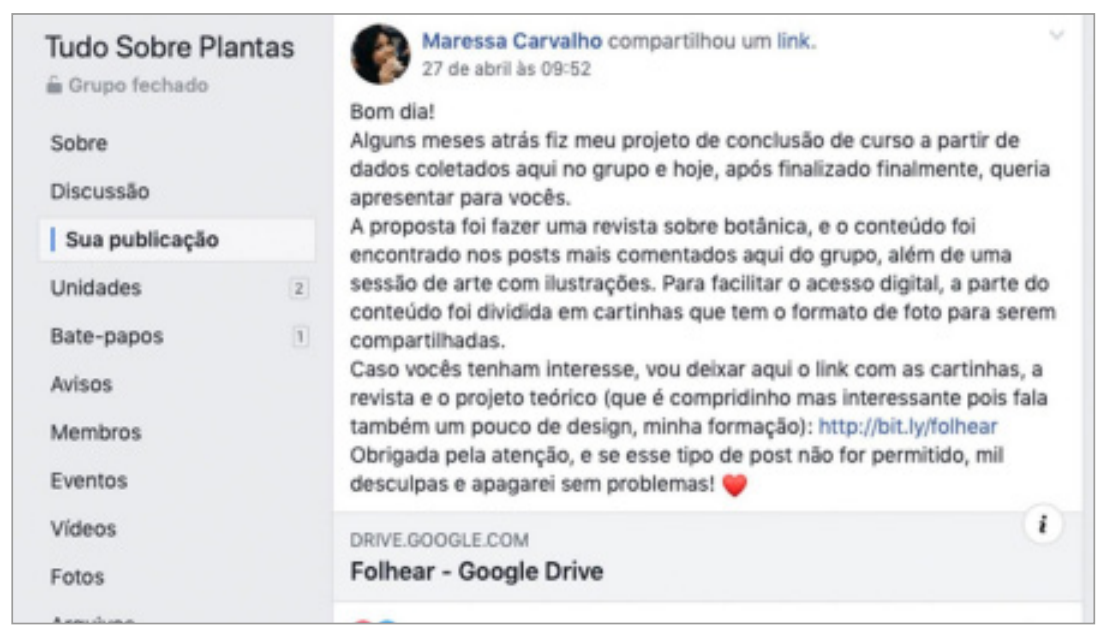

FIGURA 11: Foto de tela da postagem da revista no grupo "Tudo Sobre Plantas". Fonte: Acervo da autora, 2019.

No grupo, a postagem recebeu (até o presente momento), treze curtidas e sete comentários, onde se percebe o engajamento da comunidade, visto que demais postagens recebem em média oito curtidas. Nos comentários, membros novos e antigos que já conheciam a autora de outras postagens, a felicitaram pela conclusão do projeto e inclusive o adminis- 
trador do grupo, Anderson Porto, atentou sobre uma errata de conteúdo, que foi prontamente alterada.

Já no perfil pessoal da autora, a postagem ultrapassou sessenta curtidas e doze comentários. No issuu.com, plataforma onde a publicação foi postada, a revista conta com mais de duzentas visualizações. Destas postagens surgiram, inclusive, diversas propostas de colaboração em outros projetos editoriais.

\section{CONSIDERAÇÕES FINAIS}

Este artigo tinha por objetivo abordar as metodologias utilizadas na criação da publicação, trazendo reflexões e resultados sobre o processo e a finalização do projeto. Para isto, estruturou-se em três divisões, a partir dos quais foram cumpridos os objetivos específicos determinados na introdução, sendo estes: primeiramente compreender a teoria por trás da revista, identificar a metodologia projetual utilizada e apresentar a relevância do projeto gráfico/editorial realizado.

Com base nos estudos e análises apresentados, foi apresentado a elaboração da terceira edição da Folhear, tanto sua versão impressa quanto sua interação digital. É necessário ressaltar que não foram encontrados outros estudos que reunissem botânica e design, sendo assim, considera-se o projeto como sendo uma forma de contribuição para outros futuros, editoriais ou não.

Concluindo, a partir deste artigo, percebeu-se que a relação de cultivo afetivo vai muito adiante do que se pode imaginar, podendo se estender até a origem familiar de cada indivíduo. Além disso, mostrou que é possível e desejável uma interligação colaborativa de conhecimentos, criando uma conjunção projetual mais rica e melhor desenvolvida, sendo esta, então, uma resposta possível ao problema de pesquisa que norteou esta investigação.

Espera-se, por fim, que o presente trabalho e suas reflexões contribuam nas áreas de design e nas demais que foram estudadas, servindo de suporte para outras que sejam semelhantes. 


\section{REFERÊNCIAS BIBLIOGRÁFICAS}

BRANDÃO, Carlos Rodrigues. Pesquisa Participante.

8 ed. São Paulo: Editora Brasiliense, 1990.

CARNIELLO, Maria Antonia; SILVA, Roberta dos Santos; CRUZ, Maria Ap. Berbem da; GUARIM NETO, Germano. Quintais urbanos de Mirassol D'Oeste-MT, Brasil: uma abordagem etnobotânica. Acta Amazonica, Manaus, v. 40, p. 451-470, 2010. COUTINHO, André; EGGER, Daniel; FERNANDES, Marcelo; PENHA, Anderson. 8 Minutes of Collaborative Design. 2010.

DAMASCENO, Patricia Lopes. Design de jornais: projeto gráfico, diagramação e seus elementos. Disponível em: <http://bocc.ufp.pt/>.

FETTER, Luis Carlos Revistas, Design editorial e retórica tipográfica: a experiência da revista Trip (1986-2010). Porto Alegre: 2011.

FLÓREZ, Lílian Mariela Suescun. Design da experiência nos jardins botânicos. Rio de Janeiro: 2011.

FONTOURA, Antonio Martiniano. A Interdisciplinaridade e o Ensino do Design. Revista Científica de Design, Londrina, v.2, n.2, p. 86-95, 2011.

FONTANA, Isabela Montovani; HEEMANN, Adriano; GOMES FERREIRA, Marcelo Gitirana. Design Colaborativo: Fatores Críticos para o Sucesso do Co-design. $4^{\circ}$ Congresso Sul Americano de Design de Interação, 2012. GRUSZYNSKI, Ana Cláudia. Design editorial e publicação multiplataforma. Intexto, Porto Alegre, UFRGS, n. 34, p. 571-588, 2015. DOI: 10.19132/1807-8583201534.571588. LOBATO, Gerciene de Jesus Miranda; LUCAS, Flávia Cristina Araújo; JUNIOR, Manoel Ribeiro de Moraes. Estética, crenças e ambiência: as representatividades das plantas 
ornamentais em quintais urbanos de Abaetetuba - Pará.

Ambiência Guarapuava, Paraná, v. 13, n. 1, p. 135-149,

2017. ISSN 2175-9405. DOI: 10.535/ambiencia.2017.01.09.

LUPTON, Ellen. Intuição, ação, criação - Graphic

Design Thinking. São Paulo: Editora G. Gili, 2013.

PIMENTA, Gustavo da Cunha. Introdução ao Design

Colaborativo. 2017. Disponível em: https://medium.com/@

gustavocpimenta/introdu\%C3\%A7\%C3\%A3o-ao-design-

colaborativo e30da17dd029. Acesso em: 30 set. 2018.

SHEA, Andrew. Designing for social change:

strategies for comunity-based graphic design.

New York: Princeton Architetural Press, 2012.

TAVARES, Augusto Gowert. Design e

empreendedorismo social: desenvolvimento

do aplicativo “Levo UFPel”. Pelotas, 2018. 